\title{
BURIAL MOUNDS OF THE SAMARA REGION IN THE FOCUS OF SATELLITE IMAGES
}

(C) 2020

Valkov Denis Vladimirovich, head of Archeological Studies Department «Universal Research and Studies» Research and Development Centre (Samara, Russian Federation)

Abstract. The paper focuses on two archaeological problems - the correctness of the accounting system for archaeological monuments and the effectiveness of their detection, especially in the areas of upcoming construction work. The urgency of the problems is revealed by the author on the history of the study of the burial mound «Samarsky (Prosvet) I» as well as on the example of the survey site analysis of heterogeneous data in Earth remote sensing (ERS). It was concluded that the burial mound had been examined by at least 8 expeditions within the time period of 1973-2016. During this time, the accumulated errors in the description had led to the situation when this burial mound, having a single name, was recorded twice in two different administrative districts, having 2 difference reference numbers in the system of accounting for objects of the archaeological heritage of the Samara Region. The author created a set of ERS data for the area of the burial mound, which included archival and modern satellite images. Then all the data and the locations of the mounds identified by the previous researchers were brought to a single projection by means of a purpose designed software. From 31 to 180 areas of specific contrast pixilation are allocated according to various ERS data. The locations of all mounds previously identified in the field match them. Consequently, many of these areas may correspond to fully agriculturally plowed mounds, the safety of which is endangered by the close oil pipelines construction sites. This method was used to check the territory of four more burial mounds surveyed within 2015-2017 time period and located on the construction sites. Mounds that hadn't been identified by researchers earlier and consequently damaged during the construction work were found. The author comes to the conclusion that the field archaeological survey should be preceded by the analysis of heterogeneous remote sensing data (ERS); the most reliable method is the study of the burial mounds by means of excavation of a «wall-to-wall» area covering the inter-mound space. However, this method, being the most expensive, requires adjustments based on the ERS data and other non-invasive methods.

Keywords: Samara Region; burial mound «Samarsky (Prosvet) I»; burial mound «Nikolaevka I»; burial mound «Mikhailovsky II»; burial mound «Konezavod II»; analysis of the Earth Remote Sensing Data (ERS Data); GIS; satellite images; accounting of objects of archaeological heritage; destruction of archaeological monuments/landmarks.

\section{ВЫМЕРШЕЕ ПЛЕМЯ КАЛУСА КАК ГЕГЕМОН ЮЖНОЙ ФЛОРИДЫ В XVI-XVII ВЕКАХ: ПРИЧИНЫ ЕГО ВОЕННОГО ЛИДЕРСТВА СРЕДИ ДРУГИХ НАРОДОВ ФЛОРИДЫ}

(C) 2020

\author{
Ашрафьян Константин Эдуардович, аспирант \\ кафедры археологии, древней истории и истории средних веков \\ Московский государственный областной университет (г. Москва, Российская Федерация)
}

Аннотация. Результатом работы явилось выявление и обозначение нескольких краеугольных моментов в глубокой тысячелетней истории общества аборигенов Южной Флориды - индейцев калуса (калуза), которые привели этот народ в положение лидера в регионе. В результате исследования были объединены и использованы множественные старые письменные источники, упоминающие различные моменты соприкосновения испанцев с этой исчезнувшей цивилизаций, а также использованы новые документы - книги и диссертации ведущих профессоров Флориды и США, занимающихся проблемами исчезнувших народов региона Флориды. Помимо этого были изучены артефакты и реконструкции жизни аборигенов Южной Фориды при многочисленных посещениях музеев Флориды самим автором статьи. Была выдвинута гипотеза о важной зависимости между созданием больших многонаселенных жилищ у народа калуса, их образом жизни как рыболовов-охотников-собирателей и мобильной организацией военных сил, мобильностью всего общества в условиях ежегодных стихийных катаклизмов Флориды. Результатом работы явилось также удаление «белого пятна» в советской и российской научной литературе о достаточно древнем и нетипичном оседлом народе рыболовов-охотников-собирателей при освещении событий эпохи Великих открытий и столкновения двух миров во время испанской конкисты.

Ключевые слова: калуса; калуза; колонизация; конкистадоры; христианизация; атлатль; Маунт Ки; аборигены; Центральная Флорида; Флорида; индейцы; Северная Америка; США; калусахатчи; Ки Марко; Эрнандо де Фонтанеда; испанская корона; Понсе де Леон; Карлос; залив Эстеро; Антильские острова; индейцы; побережье Флориды; Тампа; эстуарий; общество рыболовов-охотников-собирателей. 


\section{Постановка проблемы в общем виде и ее связь с важными научными и практическими задачами}

В настоящее время тема уникального для нашего времени общества индейцев племени калуса, которое существовало в течение тысяч лет и располагалось на территории Южной Флориды, почти не рассматривалась. В недавнем прошлом случались единичные попытки рассмотреть этот вопрос, так же как и недавние любительские статьи на русском языке. В Советском Союзе и в России на уроках истории и при преподавании в вузах можно отметить довольно редкое упоминание этого племени, а иногда и полное незнание истории Флориды при рассказе о Великих географических открытиях, а также конкисты восточной части юга Америки. Это является существенным пробелом в советских и российских научных изданиях и в самом рассмотрении процессов мировой истории. Однако в Америке это уникальное общество рыболовов-охотников-собирателей являлось предметом гордости и многочисленных раскопок во Флориде в 1990-2000-х годах. Многие из названий исчезнувшего племени до сих пор существуют на территории штата Флорида благодаря оставшимся названиям из языка калуса: например, наименование третьего по величине города Флориды - Тампа - означает на языке племени калуса «огненные палки». Научное значение и практическое приложение данной работы весьма велико, так как оно показывает самоизоляцию целого народа и огромного региона Южной Флориды в течение XVI-XVIII веков от попыток католической христианизации и вовлечения региона в процессы мировой истории, что тормозило развитие судоходства, пиратство, распространение христианства и множественные процессы проникновения европейцев на территорию Северной Америки. Это исследование необходимо для понимания неудачи многочисленных попыток основания поселений и миссий на территории Флориды со стороны европейцев.

Целью данной работы явилось исследование вопроса о том, как образ жизни и устои привели народ калуса в положение лидера среди всех других народов Южной Флориды в XVI-XVII веках.

Объект исследования: общество аборигенов югозапада Флориды - племя калуса.

Предмет исследования: религия, образ жизни племени калуса на момент мировой истории после 1513 года (когда Флорида была анонсирована как территория испанской короны).

Круг последних исследований и работ, в которых рассматривался народ калуса как уникальное общество рыболовов-охотников-собирателей, достаточно широк - это публикации и Университета Южной Флориды в Тампе и Санкт-Петербурге (Флорида), и Университета Флориды в Гейнсвилле об уникальных местах раскопок в Марко Поло, Ки Марко (Флорида), это ряд публикаций на тему калуса профессора Маркварда, энтузиаста мистера Дугласа Пека, пересекшего несколько раз океан по пути Христофора Колумба и повторившего в точности путь Понсе де Леона, и переписавшего историю всей Флориды профессора Ганнона, профессоров Кушинга, Мила- нича, Фьюжина, Фрэнсиса, Томпсона, Видмера, Ворса, Ханна, Снэп и еще целого ряда ученых. Все их работы постоянно добавляют новые интереснейшие факты об открытии Флориды и о уникальных народах, которые существовали на ее территории за сотни и тысячи лет до появления европейцев.

Поскольку народ калуса исчез в XVIII веке и у него не было своей письменности, то исторические документы свидетелей того времени - испанцев и археологические данные явились единственными доступными источниками для изучения этого удивительного народа, ведущего оседлый образ жизни необычного сочетания рыболовов-охотников-собирателей, с высокоразвитой системой строгой иерархии общества. Именно поэтому для выводов были использованы различные документы из первоисточников, которые были написаны испанцами-свидетелями, видевшими и имевшими дело с исчезнувшим народом калуса. Эти источники были доступны в переводах с испанского на английский и русский языки и включали таких авторов, как Берналь Диаз, Кабеза де Вака, миссионер-иезуит Рогель, губернатор Флориды и Кубы в 1567 году - Менендез и, конечно, проведший 17 лет в плену у индейцев калуса Эскаланта де Фонтанеда. Для полного анализа и изучения вопроса автор посетил многие музеи Флориды, в число которых входили: Florida Museum of Natural History, De Soto National Memorial, Marco Island Historical Museum, Collier County Museum, Mount Key Archeological State Park, South West Florida Museum of History, Calusa Heritage Trial Rendell Research Center at Pinellas. В результате изучения выставленных там артефактов, реконструкций макетов жилищ и образа жизни и верований индейцев калуса были выделены новые моменты и обоснован механизм развития общества, которое привело к гегемонии племени в регионе Южной Флориды.

В данной работе мы рассмотрели ряд факторов, приведших индейцев калуса к статусу племенигегемона в районе Южной Флориды, которому удалось почти 250 лет сохранять свою независимость, свою самобытную культуру и религию от испанской короны и не быть вовлеченными в процессы христианизации и контакт с европейцами.

\section{Основная часть}

Необходимо сказать о том, что в 70-е годы XX века археологом-энтузиастом, профессиональным военным и дайвером Вильямом Роялом (William Royal) были найдены останки человека в городе Норд Порт в месте Warm Mineral Springs во Флориде, США. Ocтанки были датированы (углеродным анализом) в десять тысяч лет [1, p. 137-145]. Это открытие изменило существующее представление о овремени движения Homo sapiens по Северной Америке, сдвинув его на четыре тысячи лет назад [1, p. 165; 2, p. 310-322].

Историю самого народа калуса связывают с культурой калусахатчи, история которой растянулась почти на две тысячи лет - с 100 года до н.э. до 1763 года н.э. - и имеет несколько временных рамок и периодов, согласно археологическим данным [3, p. 5]. Археологическая таблица показывает 5 южно-флоридских культурных периодов под общим названием калусахатчи: I - с 100 года до н.э. по 500 год н.э.; II - с 
500 по 1200 года н.э.; III - с 1200 по 1350 год; IV - с 1350 по 1500 года и $\mathrm{V}$ - с 1500 по 1763 год, когда последний из калуса был зафиксирован в испанских документах. Эти различия были обоснованы уровнем моря и были выстроены в сравнении с периодами миссиссипской культуры в работе Маркварда [3, tabl. 2].

Не будем подробно рассматривать эти вехи и сосредоточимся на более важном для нашей статьи времени - периоде калусахатчи V с 1500 до 1763 года [3, с. 5].

Существует два подхода к истории калуса.

Первый из них говорит о том, что народ калуса был наследником других цивилизаций, живущих на берегах Флориды уже несколько тысяч лет, и к 800 году н.э. несущая способность региона и базовая политическая структура общества уже сложились [4, p. 4-15].

А другая точка зрения заключается в том, что народ калуса стал влиятельным и его структура, которую встретили испанцы в 1513 году, была позднее зафиксирована документально как сформированная в результате контакта с испанцами [3].

Из забвения для археологии калуса вышли на свет после открытия в 1883 году ключевого места - Кеу Marco, обнаруженного Симмонсами как высокие скопления ракушек, и отмеченных Кенворси и Дугласом заброшенных систем каналов [5, p. 36]. Затем последовали раскопки Вилкинсона, Дэнфорда и в 1895 году Франка Гушинга (Gushing) [5, p. 36-37; 6 p. 290], который заключил, что многочисленные находки явились фазой некой жизни на юге Флориды. Так начался процесс возврата в историю мира целого народа Южной Флориды.

Археологические данные в данной статье взяты из посещенных автором музеев Флориды и опубликованных работ археологов, которые велись в районе Ки Марко (Кеy Marco) и других местах [5].

Самоназвание калуса (/kə'lu:sə/ kə-LOO-sə) означает «свирепый народ», о чем писал еще свидетель того времени испанец Фонтанеда [7, p. 5].

Письменные источники о калуса мы можем найти у испанцев, свидетелей тех событий, таких как Берналь Диас Дель Касти́льо, Кабеза де Вака и Бартоломе де Лас Касас [8]. Интереснейшие факты мы можем найти в книге побывавшего в плену у калуса испанца Фонтанеда (Hernando de Escalante Fontaneda) [7]. В 1549 году испанцев, потерпевших кораблекрушение на пути из Картахены в Испанию около современного залива Бискейн, захватили индейцы калуса. Среди них был и Эрнандо де Эскаланте Фонтанеда. Все выжившие или умерли, или были принесены в жертву богам калуса [7, p.6]. А Эрнандо Фонтанеда пощадили, так как он был тринадцатилетним мальчиком. Он оставался в столице калуса Маунд-Ки более 17 лет - до своих 30 лет [4, p. 7], за это время выучил четыре языка местных народов, был освобожден и стал переводчиком первого губернатора Флориды и Кубы - Менендеса. Кроме того, данные для понимания жизни калуса можно найти из переписки испанских проповедников францисканцев и иезуитов, а также от людей, сопровождавших губернатора Флориды и Кубы Менендеса в 1565 году, который встречался с королем калуса Карлосом [9, p. 20; 10, p. 10].
Впервые калуса для европейцев стали известны после того, как была совершена экспедиция Понсе де Леона, посланная для открытия Земли Бимини и открывшая новую землю, которую назвала Флоридой и объявила ее собственностью Испанской короны [11, c. 346-346]. Однако важная часть планов экспедиции - основание поселения - не была осуществлена, так как испанцы встретили неожиданное яростное сопротивление со стороны аборигенов, которые попытались захватить корабль и выслали против них сначала 20 , а потом 80 каноэ [4, p. 6-7; 11, с. 346], причем в некоторых каноэ умещалось до 40 человек, то есть на испанцев напали около 600-800 индейцев [2, p. 176]. Поскольку в экспедиции Понсе де Леона было всего лишь 65 человек, включая женщин, то вступать в смертельную схватку Понсе не стал, ограничившись перестрелкой с аборигенами [11, с. 264].

Из этого эпизода мы видим, что калуса смогли мобилизовать большие военные силы в очень короткие сроки - всего за пару дней, это дает некоторое представление о военных возможностях калусы и о том, что они были высоко организованы в военном отношении уже до прихода испанцев [4, p. 12]. В свете сказанного выше интересно рассмотреть, почему калуса могли выставить такие силы и откуда у них была такая мобильная военная организация.

Посмотрим на общество индейцев калуса с разных сторон, чтобы понять, как они могли прийти к тому, чтобы именно их племя стало гегемоном Южной и Центральной Флориды в XVI-XVII веках. Выберем для этого несколько моментов:

1) место обитания народа калуса и особенности Флориды;

2) устройство государства калуса;

3) религия калуса;

4) быт и воспитание детей у калуса;

5) организация, военные технологии и мобильность общества калуса;

6) инженерные достижения калуса и специфика построек их жилищ;

7) иммиграции индейцев Антильских островов во Флориду.

Было бы уместно обобщить факты и развить идею, почему калуса стали гегемонами в Южной Флориде как до испанцев, так и после их прихода и смогли удерживать в сфере своего влияния множество племен Центральной и Южной Флориды, заставляя их отказываться от союзов с испанцами.

1. Место обитания и жизни народа калуса давало им постоянный источник получения круглогодичного питания в эстуариях Мексиканского залива, независимо от погодных условий или смены года $[9$, р. $3-$ $5 ; 4$, p. 77]. А это является важным фактором независимости калуса и создания нового типа общества рыболовов-охотников-собирателей с упором на рыболовство, дающего им до $80 \%$ всей пищи [11]. То есть они были отличны от других племен, которые занимались или земледелием, или охотой, или собирательством и зависели от сезонности погоды и времени года. И эта независимость от погодных условий или смены года в получении круглогодичного питания является первым важным фактором возвышения общества калуса над другими племенами Флориды. 
2. Устройство государства калуса. Согласно де Фонтанеда, «мир калусы был сложным вождеством, во главе с королем калусы - Карлосом. Карлос, а до него и его отец, которого звали Сенкене, были владыками пятидесяти народов» и множества городов, в том числе и нынешнего города Тампы, который он описал как огромный город калуса [7, p. 2-7].

Общество индейцев калуса имело ярко выраженную социальную градацию. Оно состояло из привилегированного сословия, простолюдинов, ремесленников, религиозной прослойки, воинов и семьи верховного лидера (короля народа калуса), из которой происходили военный начальник и духовный лидер [6, с. 7-8]. Простолюдины, ремесленники, воины, представители привилегированного сословия, торговцы и вожди жили вместе в просторных одноэтажных и двухэтажных домах, способных вместить до 2000 человек [7].

Устройство государства калуса было организовано вокруг столицы в Ки Марко [12, р. 227], строгая вертикаль власти в обществе была неразрывно связана с религиозной поддержкой [9, р. 18] и давала возможность быстрой и четкой организации и мобилизации всех сил на борьбу с природными катаклизмами и с любым внешним врагом, что являлось еще одним фактором, способствующим возвышению калуса над другими племенами.

3. Важнейшее место занимали и религиозные взгляды калуса. У индейцев калуса была сложная религия [13, р.621], основанная на пантеоне богов, жреческой касте и верховной власти [13, р. 643-649], а правитель, король калуса, считался выразителем божественной воли [7, p. 4]. Живя во Флориде, калуса, безусловно, знали и умели предсказывать по поведению морской фауны и животных сезонные ураганы, шторма и тому подобное, что способствовало вере в своих богов. Эти же ежегодные сезонные катаклизмы мобилизовывали общество индейцев калуса, которое быстро и мобильно эвакуировалось во время ненастий и укрывалось. Религия калуса, с их человеческими жертвоприношениями [13, р. 641], почитанием предков (в отличие от многих других индейских племен, где отношение к пожилым было негативным), обожествлением короля калуса и безоговорочным подчинением его воле, приводила к полной консолидации общества, в котором жизнь ради общества была выше жизни каждого индивидуума. О том, что у калуса была троица богов, каждый из которых управлял миром, обществом и войной, а также то, что у человека есть три души - в зрачке, тени [2, р. 291] и в отражении, - показывает триединство такое же, как и во многих религиях мира, приспособленное для своего образа жизни и способствующее консолидации общества через общую и понятную веру. В результате всего мы понимаем, что религия была следующим важным фактором, способствующим становлению общества индейцев калуса на порядок выше, чем другие племена индейцев Флориды и Антильских островов.

4. Быт и воспитание у калуса. Воспитание детей в обществе калуса проходило без наказаний и при большой свободе [9, р. 44-59], что делало их свободолюбивыми людьми с отличной физической подготовкой, основанной на образе жизни охотника, заставляющей держать в форме тело, мышцы и развивающей реакцию из-за ежедневного труда по добыче еды морской и прибрежной фауны. Их высокий рост - на две головы выше испанцев [2, с. 279] и других индейцев, прекрасное тело были также следствием их питания и образа жизни, что способствовало их психологическому и моральному возвышению над другими аборигенами.

Образ жизни калуса и построенная на этом религия давали повод относиться к другим народам, занимающимся разведением кукурузы или занимающимся собирательством, как к более низкому обществу, и вызывали отвращение от их образа жизни [4, p. 77].

Все вышеперечисленное также было фактором, способствовавшим возвышению в моральном и психологическом плане самих калуса над остальными народами [4, р. 72-78], в том числе и над низкорослыми испанцами.

5. Организация и военное преимущества калуса следовали из их образа жизни, религии и быта: тренировки по массовому перемещению людей у калуса были постоянными, так как каждый год в Мексиканском заливе до сих пор появляются (как было сказано выше) ураганы, штормы, смерчи и сильные ветра, которые достигают во Флориде огромной скорости, до 250-300 км в час [14]. Эвакуация в таких случаях всегда должна быть быстрой и мобильной. Так что мобильность, быстрота организации эвакуации или мобилизации большого количества людей, которая практиковалась в течение сотен и тысяч лет, была нормой, в отличие от других народов, живших во внутренних районах, и выдвигала калуса на высокую ступень по сравнению с другими.

Атлатль - простое и отличное оружие, которое мы находим у калуса, искусно применялось ими в военных целях и целях охоты [2, р. 278-280]. Оно было не менее грозным, чем аркебузы испанцев, и, естественно, лучше, чем луки и стрелы, и эффективнее обычного копья, поскольку развивало скорость до 130 км в час.

Еще необходимо подчеркнуть наличие класса воинов, которые занимались только военными действиями [6, р.9], что свидетельствует о прообразе профессиональной армии, и это также ставило калуса гораздо выше, чем общество просто собирателей или охотников у других племен.

Калуса была самым мощным государством в Южной Флориде, и они были способны выставить достаточное количество воинов, отразить и сдержать испанские силы, как это было с Понсе де Леоном в 1513 и 1521 годах и в нескольких промежуточных стычках с испанцами в этот период. В 1568 году король калусы направил триста (!) каноэ в залив Тампа, где они атаковали испанских союзников и убили 500 человек, то есть калуса могли собрать тысячи воинов в короткие сроки для проведения военных действий $[4$, p. 7].

Из этого всего можно сделать вывод, что простые, но эффективные и мощные пусковые приспособления - атлатли [6, p. 9], постоянные походы за данью в глубь территории и военные стычки с северными соседями, наличие профессиональной прослойки воинов, вкупе с постоянной тренировкой калуса владением копьями для охоты на морскую и прибрежную фауну, их постоянные массовые ежегодные эвакуации во время штормов и ураганов - все это выводило их военную организацию на гораздо более высокий уровень по сравнению со всеми соседними племенами. 
6. Инженерные достижения калуса и специфика построек и жилищ.

Здесь хотелось бы подробнее изложить важные сведения об эффективных постройках - домах с большим количеством людей, живущих на одном пространстве [7, с. 95]. Отметим, что само расположение домов на высоких холмах, сделанных из глины с ракушками, позволяло осматривать огромные территории вокруг. Эти дома, сделанные на насыпях, достигающих 10 метров в высоту, давали калуса возможность быстро обнаруживать любую опасность, сигнализировать другим общинам звуковым, световым или другими сигналами, а в результате быстро мобилизоваться и, благодаря целому флоту каноэ, имеющемуся в их распоряжении, эвакуироваться из зоны опасности.

Обустройство их деревень и особенность их жилищ как домов, в которых умещается до 2000 тысяч человек, на высоких крепких насыпях [4, р. 9], давали им возможность широкой пограничной зоны - обзорной площадки без препятствий. Нахождение большого количества воинов внутри такого дома делало его похожим на казарму и позволяло быстрое реагировать на опасность. Поэтому в защищенных местах строились населенные пункты с домами для проживания 300-2000 человек [2, р. 260] на горе, с которой обозревается все вокруг: невозможно было ни напасть неожиданно, ни даже близко подойти незамеченным.

Хорошая военная организация калуса, по сравнению с другими племенами, живущими по соседству, явно основана на наличии построек для проживания казарменного типа. Моментально собрать военную силу в несколько сот человек не представляло труда для индейцев калуса. А при наличии нескольких соседних поселений с большими домами, недалеко расположенных, - выставить в короткие сроки и несколько тысяч человек для защиты или для нападения.

Отдельно следует сказать о каноэ, производством которых калуса отлично владели, которые были предметом их обмена с другими народами и которые вмещали до 40 человек (!) [5]. Каноэ являлись главным средством для быстрого и надежного передвижения в море (связанных для устойчивости как катамараны), среди мелких рек и в болотистой местности.

Сама столица калуса - Маунд Ки - представляла собой остров площадью 51 гектар с центральной системой каналов и насыпями высотой более девяти метров [4, р. 9]. Залив Эстеро - это место со множеством устричных отложений, что затрудняет навигацию даже для современных лодок. Таким образом, «при создании столицы оборонительные аспекты могли быть более важными и в ущерб легкости снабжения» [4, p. 9-11].

Как мы видим, строительство домов на высоких насыпях для нескольких десятков, сотен и даже до 2000 человек [4, p. 5] было важным преимуществом калуса перед другими аборигенами, населяющими Флориду. Эти насыпи были идеальным местом обзора, система каналов позволяла сделать само место защищенным от нападений извне. А дома с множеством проживающих в них жителей были образом домов-казарм, с хорошей системой наблюдения и быстрой мобилизацией воинов и населения. Система каналов и наличие большого флота каноэ способствовали возвышению в военном отношении калуса в регионе Центральной и Южной Флориды.
7. Иммиграция индейцев Антильских островов во Флориду в XVI веке.

Во-первых, сам народ калуса имел большую демографическую базу, в восемь раз превосходящую ту, что обнаружена во внутренних районах $[9$, p. 10 12], поэтому политическое превосходство через военное завоевание превосходящими в разы силами было легко установить на соседних землях Южной и Центральной Флориды. Этот же демографический фактор народа калуса и географически обширная территория, гораздо большая, чем у других групп в то время, были важнейшими причинами гегемонизации народа калуса в регионе.

Поскольку Куба соседствует с Флоридой, а на антильских индейцев еще с 1494 года со стороны испанцев постоянно велась охота для захвата аборигенов и привлечения их к рабскому труду на золотых и серебряных рудниках Эспаньолы и Кубы [15], то понятно, что у них был единственный путь - иммигрировать во Флориду, и это было их последнее прибежище. С собой они принесли и страшные рассказы про испанцев, вызвавшие негативное восприятие испанцев еще до прихода их самих на земли Флориды [7, p. 3]. Это было далеко не последней, но важной причиной, по которой христианские миссии были безуспешны и заканчивались провалом, часто смертью испанских монахов и священников разных орденов в XVI-XVII веках, о чем мы можем прочесть как в исследованиях о христианских миссиях [16], так и в воспоминаниях испанцев, побывавших в плену у индейцев [7; 17].

\section{Заключение}

Таким образом, все вышеперечисленные факторы: 1) место обитания народа калуса и особенности Флориды, 2) устройство государства калуса, 3) религия калуса, 4) быт и воспитание детей у калуса, 5) военные технологии в сочетании с мобильностью общества калуса, 6) инженерные достижения калуса и специфика построек их жилищ, а также 7) иммиграции индейцев Антильских островов во Флориду, вызванная приходом испанцев в Америку, - все это в совокупности подняло государство калуса на более высокую ступень, чем его соседей, и сделало народ калуса гегемоном в Южной и Центральной Флориде в XVI-XVII веках.

\section{Список литературы:}

1. Royal W.R. The Man Who Rode Sharks. N.Y.: Dodd, Mead \&Co, 1978, 254 p.

2. Ashrafyan K.E. History of Florida by... Charleston: Create Space Publisher, 2017. 325 p.

3. Marquart W.D., Tracking the Calusa: a retrospective Southeastern Archaeology // Southeastern Archaeological Conference, Southeastern Archaeology. 2014 June. Vol. 33 (1). P. 1-24.

4. Thompson V.D., Worth J.E. Political Ecology and the Event: Calusa Social Action in Early Colonial Entanglements // Archeological Papers of the American Anthropological Association, 2018 July, Vol. 29 (1). P. 68-82.

5. Widmer R.J. The Evolution of the Calusa: A Nonagricultural Chiefdom on the Southwest Florida Coast. Tuscaloosa: University of Alabama Press, 1988. 352 p.

6. Snapp A.L. The world of Calusa: Dis. ... Dr of sciences philosophy. Oxford: University of Oxford, 1999. 325 p. 
7. Fontaneda H.D. De Memoria de las cosas y costa y indios de la Florida [Internet] // https://biblioteca.org.ar/ libros/131873.pdf.

8. Кастильо Б.Д. История, биографии и мемуары. М.: Форум, 2000. 400 c.

9. Hadjo H. The Calusa: A Savage Kingdom? Regresión Magazine, Summer 2016 [Internet] // https://archive.org/stream/TheCalusaASavageKingdom.

10. Meras G.S. Pedro Menendez de Aviles and the conquest of Florida: a new manuscript. Gainesville: University Press of Florida, 2017. 432 p.

11. Кофман А.Ф. Под покровительством Сантьяго. Испанское завоевание Америки и судьбы знаменитых конкистадоров. СПб.: Крига, 2017. 1032 с.

12. Hann J.H. Missions to the Calusa (Florida Museum of Natural History: Ripley P. Bullen Series) Florida Heritage Publication. Gainesville: University Press of Florida, 1991. 479 p.

\section{THE EXTINCT CALUSA TRIBE AS THE HEGEMON OF THE SOUTH FLORIDA IN THE XVI-XVII CENTURIES: REASONS FOR ITS MILITARY LEADERSHIP AMONG OTHER ABORIGINES OF FLORIDA} (C) 2020

Ashrafyan Konstantin Eduardovich, postgraduate student of Archaeology, Ancient History and History of the Middle Ages Department Moscow Region State University (Moscow, Russian Federation)

Abstract. The result of this work was the identification and designation of several cornerstones in the deep thousand-years history of the aboriginal society of South Florida - the Calusa Indians, who led this people to the leader position in the region. The results of the study combined and used numerous of old written sources that mention various points of contact between Spaniards and disappeared civilizations, as well as new documents - books and dissertations, thesis of leading professors of Florida and the United States, dedicated to the extinct peoples of the Florida region. In addition, artefacts and reconstructions of local life in South Florida were investigated, studying them during numerous visits to Florida museums by the author. It has been hypothesized that there is an important link between the creation of large dwellings among the Calusa people and their way of life as a fishing-hunting-gathering society with the mobile organization of the armed forces and the mobility of the entire community in the face of annual Florida natural disasters. The result of the work was also an elimination of the «white spot» in the Soviet and Russian scientific literature about a fairly ancient and atypical settled people of fishermen-hunter-gatherers when covering the events of the era of great discoveries and the collision of two worlds during the Spanish conquest.

Keywords: Calusa; colonization; conquistadors; Christianization; atlatl; mount Key; natives; Central Florida; Florida; Indians; North America; USA; Caloosahatchee; Key Marco; Hernando de Fontaneda; Spanish crown; Ponce de Leon; Carlos; Estero Bay; Antilles; Indians; Florida coast; Tampa; estuary; society of fishermen-hunter-gatherer.

\section{ПИРАТСКАЯ РЕСПУБЛИКА НА БАГАМСКИХ ОСТРОВАХ: ПРИЧИНЫ ВОЗНИКНОВЕНИЯ И ВЛИЯНИЕ НА СИСТЕМУ УПРАВЛЕНИЯ ОСТРОВАМИ} (C) 2020

Паутов Дмитрий Алексеевич, аспирант кафедры новой, новейшей истории и методологии Московский государственный областной университет (2. Москва, Российская Федерация)

Аннотащия. Предметом исследования являются военно-политические, экономические, идеологические и природно-географические причины возникновения и особенностей организации Пиратской республики на Багамских островах. Объектом исследования выступают общественные отношения, складывавшиеся в процессе становления и развития пиратского сообщества как особой социальной группы, его экспансии на Багамские острова Карибского бассейна в XVII-XVIII столетиях. Особое внимание уделяется взаимоотношениям Британской Короны с пиратами и факторам, влияющим на трансформацию этой политики. Автором подробно рассмотрены политико-правовые особенности организации и функционирования системы публичной власти на Багамских островах в период пиратского господства. Методологию исследования составили исторический, структурный, системный и сравнительный методы, что позволило сформулировать теоретиче- 